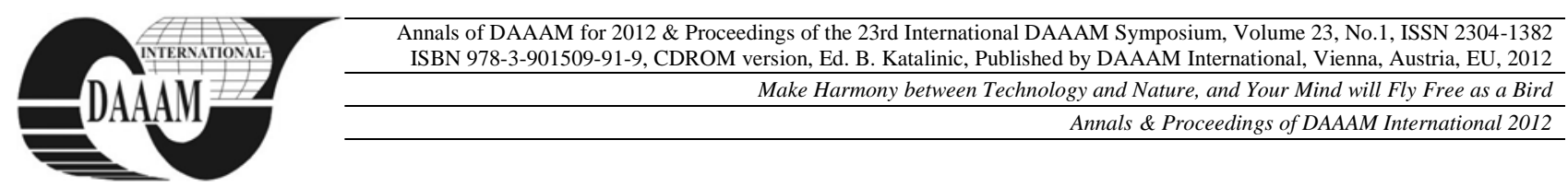

\title{
IMPROVING THE QUALITY OF THE MACHINING PROCESS THROUGH NEW TECHNOLOGIES
}

\author{
JAMBOR, J[aroslav]
}

\begin{abstract}
This paper describes the functional surfaces creation turned by the mixed cutting ceramics or coated carbide changeable insert. The hard turning process was realised by CNC programming in FANUC MANUAL GUIDE $i$ system at CNC machine tool. FANUC programming system contains from software which make possible to create programme by CNC codes and graphically as in CAD/CAM methods joined together into whole compact system. Automating the production process and the subsequent generation of NC code in ISO format is a developing trend in the series (mass) production. Significantly reduces production time and the main side times, unlike conventional production machinery. Author solution is in the shortened production process applied to HSC machining and grinding rather than qualitative indicators improved surface integrity. The first chapter is an introduction of paper defining the fundamental points. The second and third chapter describes the grinding replacement by the CNC turning technology with new cutting tools on practical examples and also experiments. The last chapter is conclusion and recommendations to improve the quality of machining. All this was practically demonstrated in the research organization VSM - The School of Management in Trencin, Slovakia in cooperation with MASH Integration Co. Trencin.

Keywords: hard turning, cutting parameters, quality process CNC programming, process improvement, hardened steel, grinding
\end{abstract}

\section{INTRODUCTION}

In recent years there has been significant development in Slovakia automotive industry. Much of components for the automotive industry is the result of mutual cooperation between companies engaged in car manufacturing and engineering firms to manufacture machine parts and components for automobile companies using the technology of machining.

It is turning and milling technology for $\mathrm{CNC}$ machine tools using modern control systems with computerized CAD/CAM systems appears to be an important way of improving the quality and precision manufactured components for the automotive industry [1].

As the machined material, usually hardened steel have hardness greater than $45 \mathrm{HRC}$, but in general ranges of hardness 53 to $58 \mathrm{HRC}$, reaching a maximum of 65 HRC, talking about "hard machining" as compensation for the previous grinding machining with defined cutting edge geometry. This aside is necessary to using the new cutting materials. It has good usability speed steels with coatings in the range of 45 to $50 \mathrm{HRC}$ still possible at low cutting speeds [3], [4].
For finishing machining of hard materials such as hardened steel was previously a problem due to the high temperature process of cutting, high cutting parameters and non adequate system machine-tool-workpiecefixture. Replacement of grinding by the turning tools with coated cemented carbide and ceramic cutting inserts and automated production process with the support of CAE systems to achieve the desired quality of machined surface in a shorter manufacturing time and improved accuracy of production [5]. This was realized in the CNC machining center with control system Manual Guide-i, in cooperation with the MASH Integration Co. Trencin.

\section{GRINDING REPLACEMENT BY THE DRY HARD TURNING TECHNOLOGY}

Arguably, the traditional grinding now reached the limits of their best options. Material removal volume is small, hardened surface layers of ground dominated by tensile stress components.

Unlike sanding or bush is turning shafts in the turbid state series advantages:

- Small machine investment costs,

- Short machining times,

- Shape and complex geometry of the workpiece to be implemented in a clamping,

- Smaller number of operational sections (steps) to the Semi finished components,

- No, the cost for disposal of sludge and abrasive refrigerants, because hard turning is done mostly dry.

How hard turning negative sides to be addressed is:

- Tool wear - to change the size and quality of surface,

- Less reliable process,

- Strongly intermittent cuts are difficult.

The turning point grinding meet very high requirements as mixed ceramic cutting - $\mathrm{CC}\left(\mathrm{Al}_{2} \mathrm{O}_{3}+\right.$ $\mathrm{TiCN}$ ) or $\mathrm{CBN}$. High wear resistance, hot hardness combined with high compressive strength and chemical stability and sufficient strength against breaking open, crucially determine the quality of the finished piece [6].

Mixed cutting ceramics - especially type SPK - SH2 has fine grains (to $1 \mathrm{~mm}$ ) and dispersed TiCN. This increases the hardness, wear resistance, stability and productivity of the cutting edge. It applies especially to the fine turning of stable parts with smooth cut and maintain the highest surface quality and close dimensional tolerance. CBN - eg. WURBON SPK- 
reported versus SH2 even higher hardness and toughness quarries. For hard turning is an appropriate species with a $45 \div 65 \%$ CBN.

The manufacturer offers the CA-EN tipped CBN CA or smaller monolith of CBN. The answer to the question of when and where can apply mixed cutting ceramics or $\mathrm{CBN}$, we can see directly on the practical results. In the rating test according to VDI - Directive 3324 [7] turned parts with intermittent cutting-Fig. 1 and Fig. 2.

Cutting parameters: (practical experiment of turning)

$$
\begin{aligned}
& \mathrm{v}_{\mathrm{c}}=110 \mathrm{~m} \cdot \mathrm{min}^{-1} \quad \mathrm{f}=0,15 \mathrm{~mm} / \mathrm{rev} \\
& \mathrm{a}_{\mathrm{p}}=0,1 \mathrm{~mm} \quad \text { dry CBN turning. }
\end{aligned}
$$

The next example was machining the hole with a groove for housing a pen. Here in both cases upheld the better- CBN WURBON 500th. In contrast, in the smooth section and added more uniformly comply $\mathrm{SH} 2$, thanks to much lower cost per cutting edge compared CBN CA.

The difference in time between machining with CBN or mixed cutting ceramics is because both operating at approximately the same measurement conditions. But using mixed cutting ceramics can increase the depth of cut $\left(a_{p}\right)$ and thereby reduce the number of shots and that is the time. This illustration shows the Fig. 2 - cylinder for cutting wires.

Cutting technology parameters: from practical example:

$\begin{array}{llc}\text { Tool: } & 1 & 2 \\ \text { Cutting material: } & \text { SH2 } & \text { CBN } \\ \text { Insert: } & \text { CNGN 120716S } & \text { TNGN 110305S } \\ \mathrm{v}_{\mathrm{c}}\left[\mathrm{m} \cdot \min ^{-1}\right] & 100 & 120 \\ \mathrm{f}[\mathrm{mm}] & 0,08 & 0,1 \\ \mathrm{a}_{\mathrm{p}}[\mathrm{mm}] & 3,0 & 1,2 \\ \text { number of cuts } & 4 & 10 \\ \text { machining time } & 60 \% & 100 \% \\ \mathrm{t}_{\mathrm{s}}[\mathrm{min}] & 18 & 30\end{array}$
62.

Workpiece material: X210 CrW12, hardness HRC =

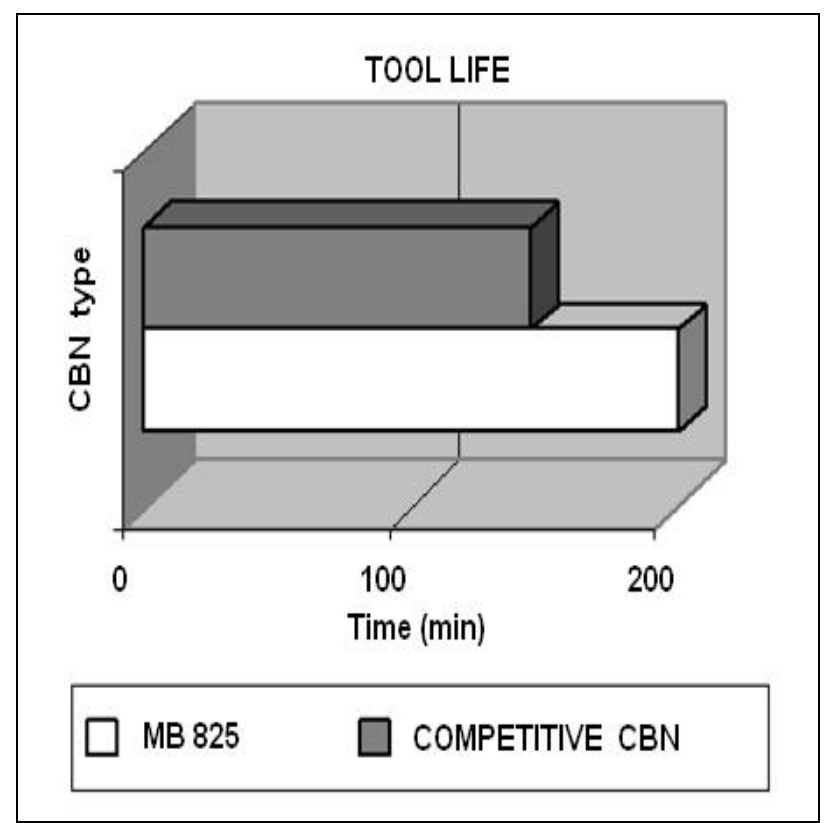

Fig. 1. CBN tool life comparison after hard turning process [6]

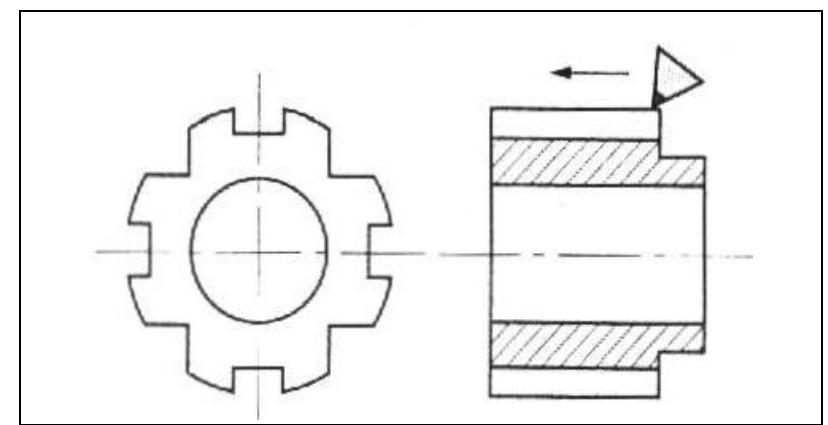

Fig. 2. Practical example of part interrupted hard turning for properties of mixed cutting ceramics and CBN comparison [6]

Another example of technological practice is turning a longitudinal cut hardened components' „STABILNE TESNENIE“ (Fig. 3) 14100.4 of the material with a hardness of 60 to 62 HRC. Workpiece turning is realized on the machine SV RB-18 and later (since 1999) on the machine KUMER-K40. Machined parts were clamp at the hole, fastened to the NC mandrel spindle machine. The tool holder CTANR $25 \times 25$ - P16 We used two types of cutting discs. The first type was used TNBN 160,408 (60 VOK /Russia/, and a second DBM-SPK Feldmühle /Germany/).

After heat treatment in protective atmosphere and abrasion after clamping both the opening and initially made a plunge grinding round, and the difficulties in achieving the desired roughness of $\mathrm{R}_{\mathrm{t}}=1.8 \mu \mathrm{m}$ respectively. $R_{a}=0.4 \mu \mathrm{m}$. The work took $t_{k}=3.2 \mu$ min. The turning diameter $38.659 \pm 0.02 \mathrm{~mm}$ to $7.3 \mathrm{~mm}$ in length $\mathrm{CC}:+\mathrm{Al}_{2} \mathrm{O}_{3}$ TiC from the two cutting parameters were tested to replace the plunge grinding. Technology was used to test wear time exceeded roughness $R_{t}=1.8$ $\mu \mathrm{m}$. It corresponds to the wear plate cutting back $\mathrm{VB}=$ $0.12 \div 0.18 \mathrm{~mm}$, which was identified from the curves the values $R_{t}=f$ (time) in the application of different cutting speed " $\mathrm{v}_{\mathrm{c}}$ ".

To achieve $R_{a}=0.4 \mu \mathrm{m}$ feed size was optimized. The best came shift value $\mathrm{f}=0.05 \mathrm{~mm} / \mathrm{rev}$. In this feed value, depth of cut $a_{p}=0.15 \mathrm{~mm}$ and $\mathrm{v}_{\mathrm{c}}=\mathrm{m} . \mathrm{min}-163$ has $\mathrm{a}$ shelf-life $\mathrm{T}=210 \mathrm{pc}$ components, machining and mechanical time $\mathrm{t}=0.11 \mathrm{~min}$ and unit time $\mathrm{t}_{\mathrm{k}}=0.5 \mathrm{~min}$. The price of one disc of CC was around $15 \mathrm{E} / \mathrm{pc}$, the first Since long-term turning on the machine SV-18 RB occurred at high speed to the saliency map and the speed had to be reduced to $\mathrm{n}=1120 \mathrm{~min}^{-1}$, therefore, since 1999 turn on the machine KUMER-K40.

When turning by dry heat, there were parts where the climate dimension is of about $0.02 \mathrm{~mm}$. Today with a chilling turn as CBN emulsion. Nowadays in the SAUER-DANFOSS Co., the SpA be done to turn the average CBN - KD 050 - CA - 160308 or TPEN DCGW 11T304.Cutting parameters for turning on the machine with PCBN Traub TNS-65-CNC with cold emulsion 5\% are:

$$
\begin{aligned}
& \mathrm{n}=1300 \div 1500 \mathrm{~min}^{-1} \mathrm{v}_{\mathrm{c}}=157 \div 182{\mathrm{~m} \cdot \min ^{-1}}^{-1} \\
& \mathrm{f}=0,05 \mathrm{~mm} / \mathrm{rev} \quad \mathrm{v}_{\mathrm{f}}=75 \div 90 \mathrm{~mm} \cdot \mathrm{min}^{-1} \\
& \mathrm{a}_{\mathrm{p}}=0,15 \mathrm{~mm} \quad \mathrm{t}_{\mathrm{s}}=0,11 \mathrm{~min} \quad \mathrm{t}_{\mathrm{k}}=0,50 \\
& \min \quad \mathrm{T}=26,4 \div 27,5 \mathrm{~min}= \\
& 240 \div 250 \mathrm{pc}, \text { at the } \mathrm{VB}_{\mathrm{k}}=0,15 \mathrm{~mm} .
\end{aligned}
$$

In addition to "hard-grinding turning point" is more practical and see reciprocal replacement. This is where the builder is required of any partial surface roughness, 
which cannot be achieved by hard turning. It is actually a replacement of rough grinding by turning when combined machining to reach the intermediate and shorter preparation times [2], [5].

Operation: Diameter turning 38, 66-0,02 $\mathrm{mm}$ x 7,3 mm

Workpiece clamping: special fixture for hole $\varnothing 35,7 \mathrm{H} 8$, case width 15,6 mm, max. $\varnothing=60,45 \mathrm{~mm}$

Material: 14109.4 (100 Cr6), after hardening to HRC = $60+2$ ad after hole grinding for clamping

Machine tool: KUMMER K40 - CNC

\section{Tool holder: SDJCL 2525 M12}

Insert: a) cutting ceramics TNMN 160408, SH1 (SPK Feldmühle) or VOK 60 (Russia)

b) PCBN (BN) -DCGW 11T308 - PB050, or type TPEN $160308-$ KD 050

Cutting parameters:

$\mathrm{n}=1300 \div 1500 \mathrm{~min}^{-1} \quad \mathrm{v}_{\mathrm{c}}=190 \div 200 \mathrm{~m} . / \mathrm{min}$

$\mathrm{f}=0,05 \mathrm{~mm} / \mathrm{rev} \quad \mathrm{v}_{\mathrm{f}}=75 \div 90 \mathrm{~mm} / \mathrm{min}$

$\mathrm{a}_{\mathrm{p}}=0,15 \div 0,25 \mathrm{~mm}$

Technological wear criterion was exceeded the value of surface roughness $\mathrm{R}_{\mathrm{t}}=1.8 \mu \mathrm{m}$, what is recessing grinding makes very difficult.

Reached results:

a) without coolant

$\mathrm{T}_{(\mathrm{a})}=180 \div 210 \mathrm{pc}$

$\mathrm{T}_{(\mathrm{b})}=240 \div 250 \mathrm{pc}$

$\mathrm{R}_{\mathrm{a}(\mathrm{a})}=0,3 \div 0,4 \mu \mathrm{m}$

$\mathrm{R}_{\mathrm{a}(\mathrm{b})}=0,32 \div 0,38 \mu \mathrm{m}$

b) with UNIMET $5 \%$ coolant

$\mathrm{VB}_{\mathrm{k}}=0,12 \div 0,18 \mathrm{~mm}$

$\mathrm{VB}_{\mathrm{k}}=0,15 \mathrm{~mm}$

$\left(\mathrm{R}_{\mathrm{tmax}(\mathrm{a})}=1,8 \mu \mathrm{m}\right)$

$\left(\mathrm{R}_{\mathrm{t} \max (\mathrm{b})}=1,8 \mu \mathrm{m}\right)$

Turning time: $\mathrm{t}_{\mathrm{AS}}=0,11 \mathrm{~min}, \mathrm{t}_{\mathrm{k}}=0,5 \min$

Grinding time: $\mathrm{t}_{\mathrm{k}}{ }^{\prime}=3,2 \mathrm{~min}$

\section{AUTOMATION PROCESS OF TURNING IN MANUAL GUIDE-i CNC SYSTEM}

The shape of the individual components for the automotive industry and subsequently of time and relative complexity of the conversion work and tool paths for CNC program preparation led to the establishment of internal and external graphics support for the creation of individual programs. Under an external computer graphic-promoting wise use of CAD/ CAM systems from the technical documentation, modeling shapes of parts and final source intermediate to the setting aside of appropriate technology, options and shape correction tools, manufacturing process simulation of CNC machine to use for the appropriate postprocessor to generate $\mathrm{NC}$ program suitable for CNC machine tool [4]. Another solution is the installation of internal support system. Such a solution as an extension of classical control system called CNC FANUC Manual Guide-i. This software is an integral part of CNC machine tools.

In practice, we can meet with each of these add-series systems. The shape and control system FANUC graphic post is the same in CNC lathes and milling machines. MANUAL GUIDE-i contains elements of CAD / CAM and classical programming. CNC program can be created manually typing each CNC code as in the classical programming, but many operations consist of structures and CAD/CAM programming [6].

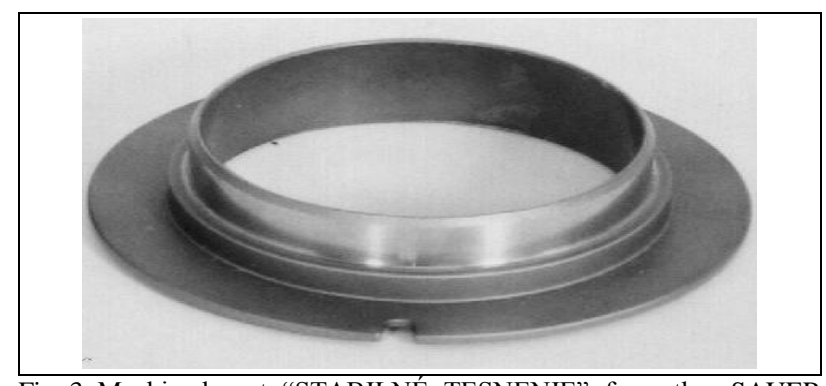

Fig. 3. Machined part "STABILNÉ TESNENIE" from the SAUER DANFOSS production process after hard turning with cutting ceramics, or with CBN [7]

The graphical menu of the windows machines CNC programmer defined data of management system for fishing cutting tools, cutting conditions, work sliding, taking the shape and dimensions and contours below. The overall structure of the CNC program, created in the Manual Guide-i contains the following structure:

1. register the name of the program and insert the required machinery and auxiliary functions,

2. define the size and shape of the blank,

3. ramp down into the turret tool change point

4. onto the turret to the starting point of beginning of the cycle machining,

5. determine the parameters of the machine cycle by clinical and graphical menu,

6. built drawings, taking the shape contour including its dimensions,

7. output setting point of the tool, tool change, stopping speed, cutting fluid etc.,

8. for using multiple operating cycles repeat procedure

9. simulation of cutting process (see on Fig. 5 and 6).

CNC program, created in the Manual Guide i, can be converted to ISO format, which is the extension Fanuc universal use.

\subsection{Program features and modes, practical example}

Higher product MANUAL GUIDE-i to work in EDIT mode (creating a change in the program), JOG (manual mode to capture and correction tools, determining the work origin cultivated parts) MEM and (graphic simulation and collision in the determination of $\mathrm{NC}$ program, run $=$ automatic machining mode $\mathrm{CNC}$ machine). Particularly important is the EDIT mode, it becomes NC program. The new program will create using software keys START, and END OF CYCLE. In the START menu, we define the beginning of the program (using predefined templates), the shape and dimensions of the blank. The menu features CYCLE programming cutting conditions, the selection of machining technology and final shape of the components utilized by shifting panels and graph icons.

In EDIT mode, also we make various changes and modifications NC program. In automatic mode, the MEM can be created graphically simulated programs, which is beneficial for control. The error in the program, we created a system alert and alarm stops running programs on it that the collision site. The animation is possible to change the size and views on the machining process as well as chart the way clinical and imaging. JOG In manual mode can be controlled machine tool using a hand wheel. 
CNC machine programmer can itself change the size of the control feed rates and spindle speeds. CNC lathe work normally in two axes, namely the horizontal-axis (axis machining of parts) and a vertical wall $\mathrm{X}$-axis perpendicular to the axis, which indicates the average of manufactured parts (see on Fig. 4).

If necessary, the cutting grooves on the circumference of a rotating head parts or drilling holes on the surface and headed out of the central axis of the workpiece, there are adjustable $\mathrm{CNC}$ lathe with $\mathrm{C}$ axis spindle and the new $\mathrm{Y}$-axis perpendicular to the axis $\mathrm{X}$.

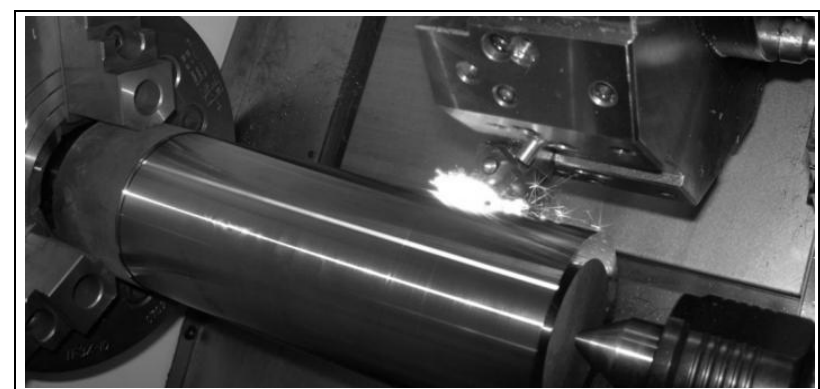

Fig. 4. Hard turning of part made of C120U steel on AERO TURN 350 BT CNC Machine tool [7]

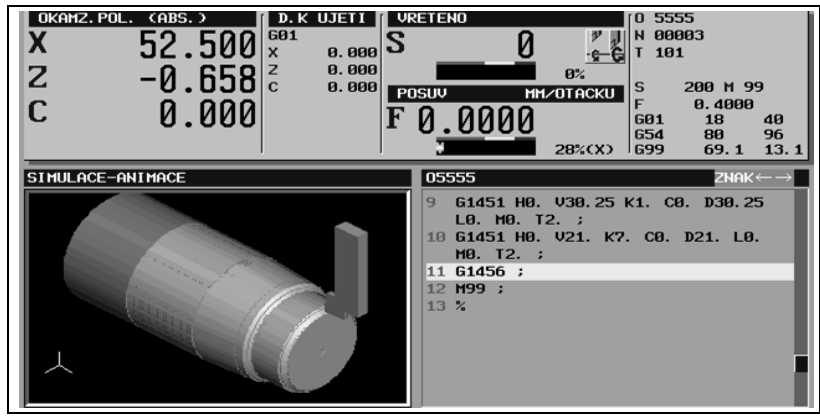

Fig. 5. Simulation hard turning process in automatic mode of $\mathrm{CNC}$ machine tool in MANUAL GUIDE-i CNC system [6]

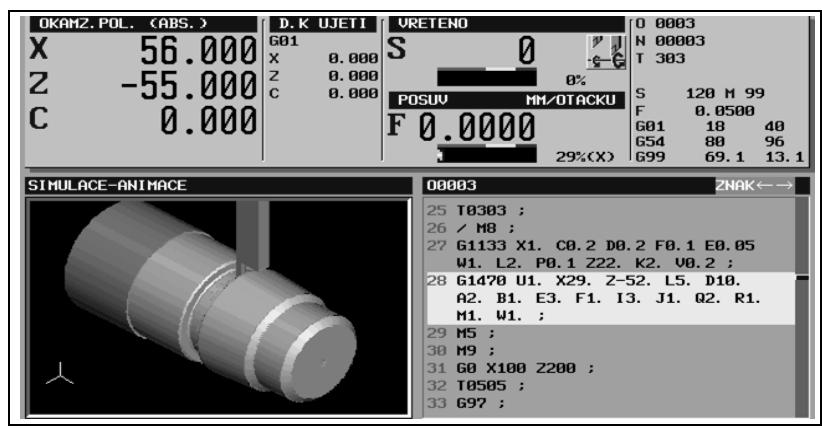

Fig. 6. Simulation of hard turning process in automatic mode of CNC machine tool in MANUAL GUIDE i CNC system (the next step) [6]

This practical application becomes a versatile CNC turning centers leading to expansion of scope and complexity of the shape of machined parts on CNC lathes (can see on Fig. 4). These software and hardware equipment of the CNC lathes leads to more efficient and flexible production and reaches more qualitative machined components for the automotive industry and reduces production times.

Cutting parameters for hard turning and grinding and I chose steered so that the achieved dimensional accuracy and surface roughness was approximately the same $(\mathrm{Ra} \leq$ $0.4 \mathrm{~mm})[8]$.

\section{CONCLUSION}

This presented paper describes the methods and various standards of CNC machine tools programming in the manufacturing (hard turning) process.

Contribution of the authors solved the problem presents an original solution of the manufacturing process with the support of FANUC CNC control system. Practical experiments confirm hardened steel grinding accuracy of compensation hard turning. The results presented in this paper can be further exploited in the process of teaching courses and programming machines and technical practice for upgrading older solutions and processes of the main and additional times, while maintaining the dimensional accuracy of machine parts. Further research will be based CNC programming parts with complex shapes see links in the author of the modern CNC machines using modern types of cutting materials for machining.

\section{ACKNOWLEDGEMENTS}

Our presented scientific paper was to connection between the theory of drilling and of industrial practice. The practical measurement of specimen part was conducted in cooperation with the VSM - The School of Management, along with industrial companies of the region of Trencin (e.g. MASH Integration Co. Trencin).

\section{REFERENCES}

[1] Danisova, N.; Sebenova, S. \& Velisek, K. (2011). Application of seguence diagram within tool change during machining, Annals of DAAAM for 2011 \& Proceedings of the 22nd International World Symposium, 23-26th November 2011, Austria center Vienna, ISSN 1726-9679, ISBN 978-3-901509-70-4, Katalinic, B. (Ed.), pp. 0459-0460, TUV, Vienna, Austria

[2] Dubovska, R.; Majerik, J. \& Chochlikova, H. (2011). Residual stress measurement by the X-ray diffraction method , Annals of DAAAM for 2011\&Proceedings of the 22nd International World Symposium, 23-26th November 2011, Austria center Vienna, ISSN 1726-9679, ISBN 978-3-901509-70-4, Katalinic, B. (Ed.), pp. 1327-1328, TUV, Vienna, Austria

[3] Dubovska, R.; Majerik, J. \& Chochlikova, H. (2011). Physicochemical state Stabilization of high strength steels machined surface, Proceedings in manufacturing systems, Vol.6, No.4, (2011) p. 75-80, ISSN 2067-9238

[4] Jambor, J.; Majerik, J. (2009). Hard Die\&Mould Milling Process with CAD/CAM System Catia V5R18 Support, Annals of $D A A A M$ for $2009 \&$ Proceedings of the 20th International World Symposium, 25-28th November 2009, Austria center Vienna, ISSN 1726-9679, ISBN 978-3-901509-70-4, Katalinic, B. (Ed.), pp. 1465-1466, TUV, Vienna, Austria

[5] Majerik, J.; Bajcik, S. (2009). Residual stresses measurement after high strenght steels grinding by high cutting speeds application, Annals of DAAAM for 2009\&Proceedings of the 20th International World Symposium, 25-28th November 2009, Austria center Vienna, ISSN 1726-9679, ISBN 978-3-901509-70-4, Katalinic, B. (Ed.), pp. 1811-1812, TUV, Vienna, Austria

[6] Majerik, J.; Jambor, J. (2010). Automation of hard turining process with Fanuc manual Guide-i support and CNC program generation, Proceedings in manufacturing systems, Vol.5, Special Number, (2010) p. 281-284, ISSN 2067-9238

[7] Majerik, J.; Sandora, J. (2012). The new progressive cutting tools and machining technology methods, FST TnUAD, ISBN 978-808075-515-7, EAN 9788080755157, Trencin, Slovakia

[8] Steiningerova, J.; Majerik, J. (2010). Surface quality analysis of $102 \mathrm{Cr} 6$ bearing steel after CC6050 insert by hard turning and by SG grinding wheel, Proceedings in manufacturing systems, Vol.5, No.3, (2010) p. 137-142, ISSN 2067-9238 